\title{
ESTRUTURA GENÉTICA DE POPULAÇÕES NATURAIS DE CRYPTOCARYA ASCHERSONIANA MEZ (LAURACEAE) ATRAVÉS DE MARCADORES ISOENZIMÁTICOS
}

\author{
Pedro Luís Rodrigues de Moraes ${ }^{1,2}$ \& Maria Teresa Vitral de Carvalho Derbyshire ${ }^{1,2}$
}

Biota Neotropica v2 (n2) - http://www.biotaneotropica.org.br/v2n2/pt/abstract?article+BN02402022002

\author{
Recebido em 09/09/2002 \\ Revisado em 30/10/2002 \\ Publicado em 29/11/2002
}
${ }^{1}$ Bolsa de Pós-Doutoramento a P.L.R. Moraes (FAPESP 99/05004-5), auxílio à pesquisa (BIOTA/FAPESP 99/05818-2);
${ }^{2}$ Laboratório de Melhoramento de Plantas, CENA/USP, Caixa Postal 96, 13400-970, Piracicaba, SP, Brasil Autor para correspondência: E-mail: plmoraes@cena.usp.br

\begin{abstract}
Genetic structure of natural populations of Cryptocarya aschersoniana Mez (Lauraceae) through isozyme markers]. Through the analysis of 39 polymorphic allozyme loci, allele frequencies were estimated from 267 individuals of 12 natural populations of Cryptocarya aschersoniana native to "Planalto forests" of the state of São Paulo and south of Minas Gerais, Brazil. Estimates of Wright's $F$ statistics were computed through the analysis of variance for obtaining unbiased estimation of corresponding parameters $F=F_{\text {IT }}, \theta_{\mathrm{P}}=F_{\text {ST }}$ and $f=F_{\text {IS }}$. Average values of $\hat{F}$ were $0.552<0.415<$ 0.275 ; those of $\hat{\theta}_{\mathrm{P}}$ were $0.395<0.335<0.279$; and those of $\hat{f}$ were $0.292<0.119<-0.039$. These results indicated that individuals within populations might be panmitic, and that the diversity among populations was fairly high, being superior to what would be expected for groups of plants having a full-sib family structure. From estimates of $\hat{\theta}_{\mathrm{P}}$ obtained for populations taken two at a time, the model of isolation by distance was employed and it has shown to be inadequate for explaining the divergence found among populations. The estimated gene flow of 0.4 migrants per generation corroborated the pronounced populational differentiation. Due to negligible $\hat{f} @ \hat{F}_{\text {IS }}$ values found, the variance effective size for each population was equivalent to its sampling number. Under a metapopulation context, considering the 12 populations sampled for the species, the effective population size was 15.4 individuals $(5.77 \%)$ for the total sampled, indicating that sampling of different populations should be an important strategy for their management.
\end{abstract} Brazil

Key words : allozymes, Lauraceae, genetic structure, Neotropics, Cryptocarya aschersoniana, Planalto forest,

Resumo - [Estrutura genética de populações naturais de Cryptocarya aschersoniana Mez (Lauraceae) através de marcadores isoenzimáticos]. Pela análise de 39 locos isoenzimáticos polimórficos, estimaram-se as freqüências alélicas referentes a 267 indivíduos de 12 populações naturais de Cryptocarya aschersoniana provenientes de Florestas de Planalto do estado de São Paulo e sul de Minas Gerais, Brasil. Foram obtidas estimativas das estatísticas $F$ de Wright pelo método da análise da variância para estimação não viesada dos parâmetros correspondentes $F=F_{\mathrm{IT}}, \theta \mathrm{P}=F_{\mathrm{ST}}$ e $f=F_{\mathrm{IS}}$. Os valores médios obtidos de $\hat{F}$ resultaram em $0,552<0,415<0,275$; os de $\hat{\theta}_{\mathrm{P}}$ foram $0,395<0,335<0,279$; e os de $\hat{f}$ sendo $0,292<$ $0,119<-0,039$. Esses resultados indicaram que os indivíduos dentro das populações devem ser panmíticos e que a diversidade entre populações foi bastante alta, sendo superior à que poderia se esperar para famílias com estruturação de irmãosgermanos. Calculando-se $\hat{\theta}_{\mathrm{P}}$ com as populações tomadas duas a duas, testou-se o modelo de isolamento pela distância que se mostrou inadequado para explicar a divergência encontrada entre as populações. $\mathrm{O}$ fluxo gênico estimado de 0,4 indivíduos por geração corroborou a pronunciada diferenciação populacional. Devido aos valores insignificantes encontrados de $\hat{f} @ \hat{F}_{\text {IS }}$, o tamanho efetivo de variância de cada população foi equivalente ao número de indivíduos amostrados. Sob um contexto metapopulacional, considerando-se as 12 populações amostradas para a espécie, o tamanho efetivo populacional foi de 15,4 indivíduos $(5,77 \%)$ para o total amostrado, indicando que a amostragem de diferentes populações deve ser uma estratégia importante para seu manejo.

Palavras-chave:alozimas, Lauraceae, estrutura genética, Neotrópico, Cryptocarya aschersoniana, Mata de Planalto, Brasil

http://www.biotaneotropica.org.br 


\section{Introdução}

A variabilidade alozímica em populações naturais de plantas tem sido intensivamente estudada (Gottlieb 1977, Nevo 1978, Brown 1979, Hamrick et al. 1979, Hamrick \& Godt 1990, Rocha \& Lobo 1998, Sousa 2001). Em espécies arbóreas, a alta variabilidade alozímica está relacionada à longevidade, ampla distribuição geográfica, e potencial para um pronunciado fluxo gênico. Essas características combinadas podem contribuir para um aumento do tamanho efetivo populacional (Sousa 2001).

O conhecimento da estrutura populacional é importante para se evitar perdas adicionais de diversidade genética em populações que são ameaçadas por atividades madeireiras, desmatamento e fragmentação de hábitat (Hall et al. 1994, Nason et al. 1997, Rocha \& Lobo 1998). A fragmentação de áreas de floresta, pelo avanço da agricultura e de outras atividades antrópicas, leva ao isolamento de subpopulações e, conseqüentemente, à deriva genética e à endogamia (Robinson 1998).

As informações sobre a variabilidade genética em populações naturais são fundamentais para o progresso de duas áreas de grande interesse atual: especiação em florestas tropicais e conservação de recursos genéticos (Buckley et al. 1988). Moraes et al. (1999), em estudo de 214 indivíduos de quatro populações naturais de Cryptocarya moschata Nees, através de 18 locos isoenzimáticos polimórficos, apontaram para o fato de que as estratégias de manejo e conservação, necessárias para a preservação da alta variabilidade genética intrapopulacional encontrada para $C$. moschata, implicariam na manutenção de populações com número alto de indivíduos. Além disso, para a preservação da espécie como um todo, a manutenção de muitas populações deveria ser provavelmente necessária. Não obstante, o atual conhecimento sobre a Mata Atlântica (sensu lato; ver Joly et al. 1999) é ainda bastante incipiente, principalmente quanto à estruturação genética populacional de suas espécies, e procedimentos adequados de amostragem para fins conservacionistas e de manejo.

O presente trabalho objetivou a caracterização da estrutura genética de populações de Cryptocarya aschersoniana Mez, através de estimativas das estatísticas $F$ de Wright, pelo método da análise de variância. A partir da estimativa não viesada de $F_{\mathrm{ST}}$, testou-se o modelo de isolamento pela distância. Adicionalmente, foram obtidas estimativas indiretas do fluxo gênico entre populações, bem como seus tamanhos efetivos intrapopulacionais e metapopulacional e o tamanho de vizinhança.

\section{Material e Métodos}

\subsection{Cryptocarya aschersoniana Mez}

A espécie Cryptocarya aschersoniana Mez pertence ao gênero Cryptocarya R. Brown, subtribo Cryptocaryineae Kosterm., tribo Cryptocaryeae Meissn., subfamília Lauroideae Kosterm., conforme a classificação de Kostermans (1957) para a família Lauraceae Lindl. Os indivíduos reprodutivos de $C$. aschersoniana são árvores de 10-35 m de altura por 20-199 cm de DAP (P.L.R. Moraes, dados não publicados). As flores são hermafroditas, trímeras, com duas séries de tépalas $(3+3), 6$ estames introrsos e 3 extrorsos, com anteras biloceladas, 3 estaminódios, ovário quase séssil e estigma inconspícuo. Os frutos são nucóides, tipo núcula, com 1,78-3,47 cm de comprimento $(\overline{\mathrm{X}}=2,50 \pm 0,28 \mathrm{~cm} ; \mathrm{N}=1.487$ frutos de 37 árvores), 1,10-3,20 cm de diâmetro $(\overline{\mathrm{X}}=2,37 \pm 0,22 \mathrm{~cm} ; \mathrm{N}=$ 1.487 frutos de 37 árvores). Os diásporos apresentam 1,38$3,00 \mathrm{~cm}$ de comprimento ( $\overline{\mathrm{X}}=2,15 \pm 0,24 \mathrm{~cm} ; \mathrm{N}=1.283$ diásporos de 36 árvores), 1,00-2,16 cm de diâmetro ( $\overline{\mathrm{X}}=1,50$ $\pm 0,15 \mathrm{~cm} ; \mathrm{N}=1.283$ diásporos de 36 árvores; Moraes \& Alves 2002). A distribuição geográfica de C. aschersoniana ocorre do Rio Grande do Sul ao Espírito Santo, com presença também em Mato Grosso do Sul, Mato Grosso e Goiás.

A identificação da espécie foi feita a partir de material herborizado e depositado no herbário da Escola Superior de Agricultura "Luiz de Queiroz" (ESA), cujos vouchers são enumerados na tabela 1. Para C. aschersoniana Mez, segundo revisão feita por Kostermans (1937, 1938), existem pelo menos três diferentes morfoespécies cujo status taxonômico permanece duvidoso quanto a se realmente representam uma única espécie biológica (Moraes \& Alves 2002). Desta forma, tem-se que os indivíduos amostrados no presente trabalho pertencem todos ao mesmo padrão morfológico encontrado nas populações do Planalto de São Paulo e sul de Minas Gerais. 


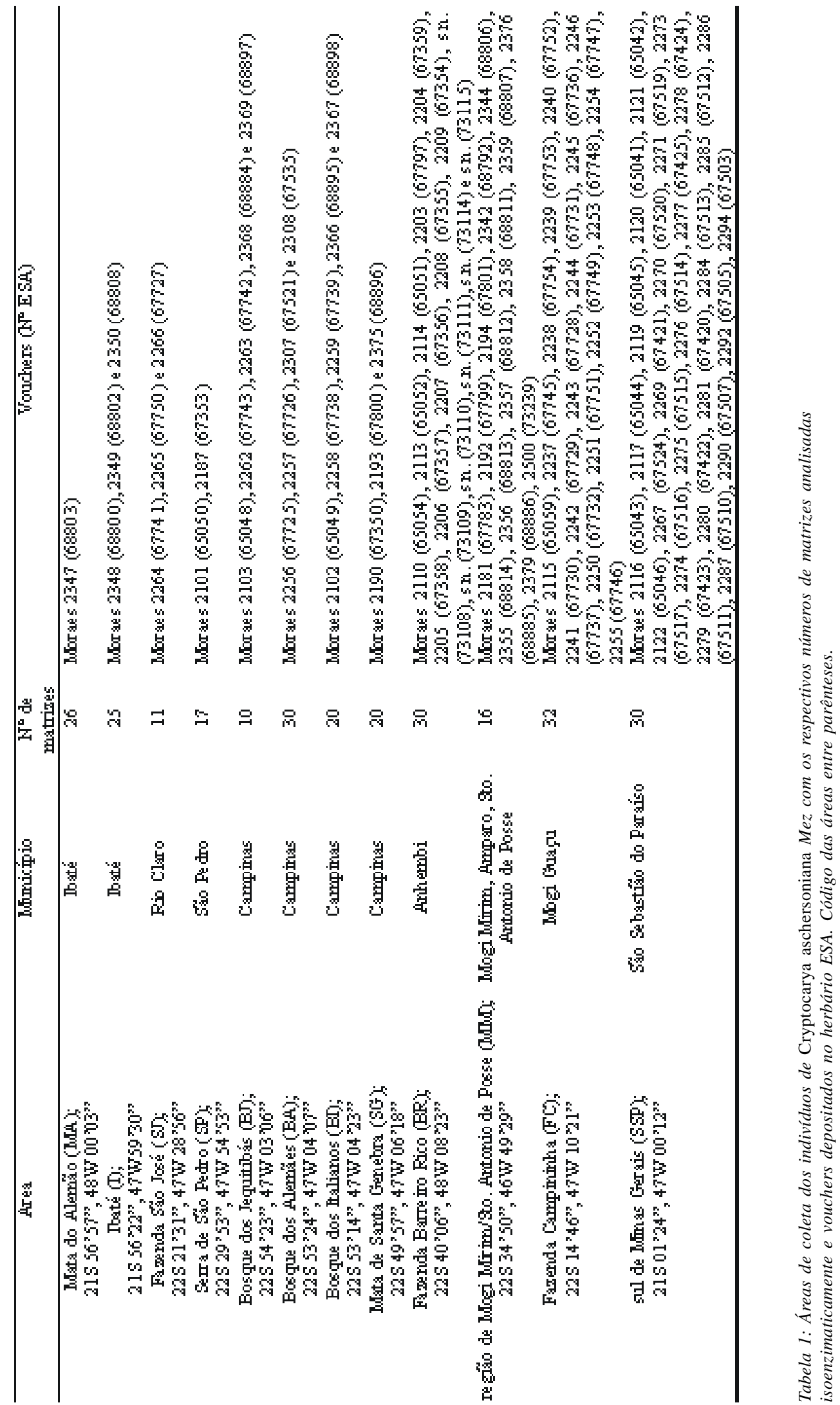




\subsection{Material vegetal e amostragem}

Um ramo foliar portador de folhas maduras foi coletado de indivíduos adultos da espécie Cryptocarya aschersoniana Mez, acondicionados em sacos plásticos, que por sua vez foram armazenados em caixas de isopor com gelo para o transporte até o laboratório. Uma vez no laboratório, foram mantidos em geladeira $\left(\cong 5^{\circ} \mathrm{C}\right)$ até sua extração e análise eletroforética após aproximadamente dois dias em média.

Nas tabela 1 e figura 1 apresentam-se as localidades cujas populações foram amostradas. Procurou-se coletar no mínimo 20 indivíduos por população, sempre que possível. Porém, em determinadas populações, quer pela inexistência desse número de indivíduos, quer pela baixa frequiência dos mesmos nas áreas estudadas, os tamanhos das amostras foram menores.

As amostras foram coletadas em diferentes fragmentos florestais com diferentes graus de conservação e tamanho. Com isto, tem-se desde: (i) fragmentos pequenos, bastante impactados e dentro de áreas urbanas, tais como os encontrados nos Bosque dos Alemães (com área de 2,07 ha, perímetro de 571,8 m e taxa de circularidade de 1,12 [D.A. Santin, dados não publicados]), Bosque dos Italianos (1,4 ha, com perímetro de 545,8 m e taxa de circularidade de 1,15 , distante cerca de $500 \mathrm{~m}$ do precedente [D.A. Santin, dados não publicados]), Bosque dos Jequitibás (área total de 10,34 ha e apenas 2,0 ha de vegetação nativa muito perturbada, com perímetro de $1.707,5 \mathrm{~m}$ e taxa de circularidade de 1,49 [D.A. Santin, dados não publicados]), e Mata do Alemão (cerca de 1 ha); (ii) fragmentos pequenos, bastante impactados e circundados por áreas agrícolas de cana-deaçúcar, pastagens ou café, tais como os de Ibaté (cerca de 1 ha), Serra de São Pedro (cerca de 2 ha), e São Sebastião do Paraíso (cerca de 4 ha); (iii) fragmento pequeno, moderadamente impactado e circundado por áreas de Reserva Biológica e Estação Experimental, tal qual a área amostrada ao longo da mata ciliar do Córrego Mariana da Fazenda Campininha (cerca de 20 ha); (iv) fragmentos médios, moderadamente impactados e circundados por áreas agrícolas de pastagens e cana-de-açúcar, tais como os da Fazenda São José (cerca de 230 ha, área I referida por Pagano \& Leitão Filho 1987), e da região de Mogi Mirim (cerca de 50 ha [D.B. Zabeu, comunicação pessoal]); (v) fragmento médio, moderadamente impactado (porção amostrada) e dentro de área urbana, tal qual o da Mata de Santa Genebra (área de 251,77 ha, com perímetro de 8.509,87 m e taxa de circularidade de 1,51 [D.A. Santin, dados não publicados]); e (vi) fragmento grande, relativamente bem conservado e circundado por áreas de pastagens e de cana-de-açúcar, como o da Fazenda Barreiro Rico (cerca de 2.200 ha, Assumpção et al. 1982, Cesar \& Leitão Filho 1990).

\subsection{Isoenzimas}

A partir do emprego de marcadores alozímicos, revelados pela eletroforese em gel de amido, fez-se a caracterização genética das populações analisadas, seguindo-se principalmente as recomendações de Alfenas et al. (1991).

A escolha dos sistemas enzimáticos para a análise genética do material em laboratório foi precedida por uma série de testes, realizados no Laboratório de Melhoramento de Plantas do CENA/USP, sendo que foram empregados géis de penetrose a $13 \%$ e tampão de extração Namkoong (solução no 1 descrita em Alfenas et al. [1991; pg.41]). Na extração das amostras, um pedaço da lâmina foliar era cortado em cerca de $1,2 \times 1,2 \mathrm{~cm}$, na região da nervura central, com o respectivo peso sendo multiplicado por 4, resultando nos equivalentes em $\mu l$ da quantidade de tampão de extração a ser utilizado na maceração da amostra.

Foram testados 31 sistemas, dos quais 19 foram selecionados (tabela 2) para as análises populacionais por apresentarem boa resolução de bandas e polimorfismo. A partir dos zimogramas gerados, obtiveram-se 39 locos polimórficos que foram empregados nas análises genéticas, a saber: Acp-1, Acp-2, Acp-3, Alp-1, Alp-2, Cat-1 e Cat-2 (método de Alfenas et al. 1991), Cat-1, Cat-2 e Cat-3 (método de Scandalios 1965), Dia-1, Dia-2, Dia-3, $\alpha$-Est-1, $\beta$-Est-1, Gdh, Got, Idh, Mdh-1, Mdh-2, Nadhdh, Nadphdh, 6Pgdh-1, 6Pgdh-2, 6Pgdh-3, Pgi-1, Pgi-2, Ppo-1, Ppo-2, Prx-1, Prx-2, Prx-3, Prx-4, Prx-5, Skdh-1, Skdh-2, Sod-1, Sod-2 e Sod-3. 


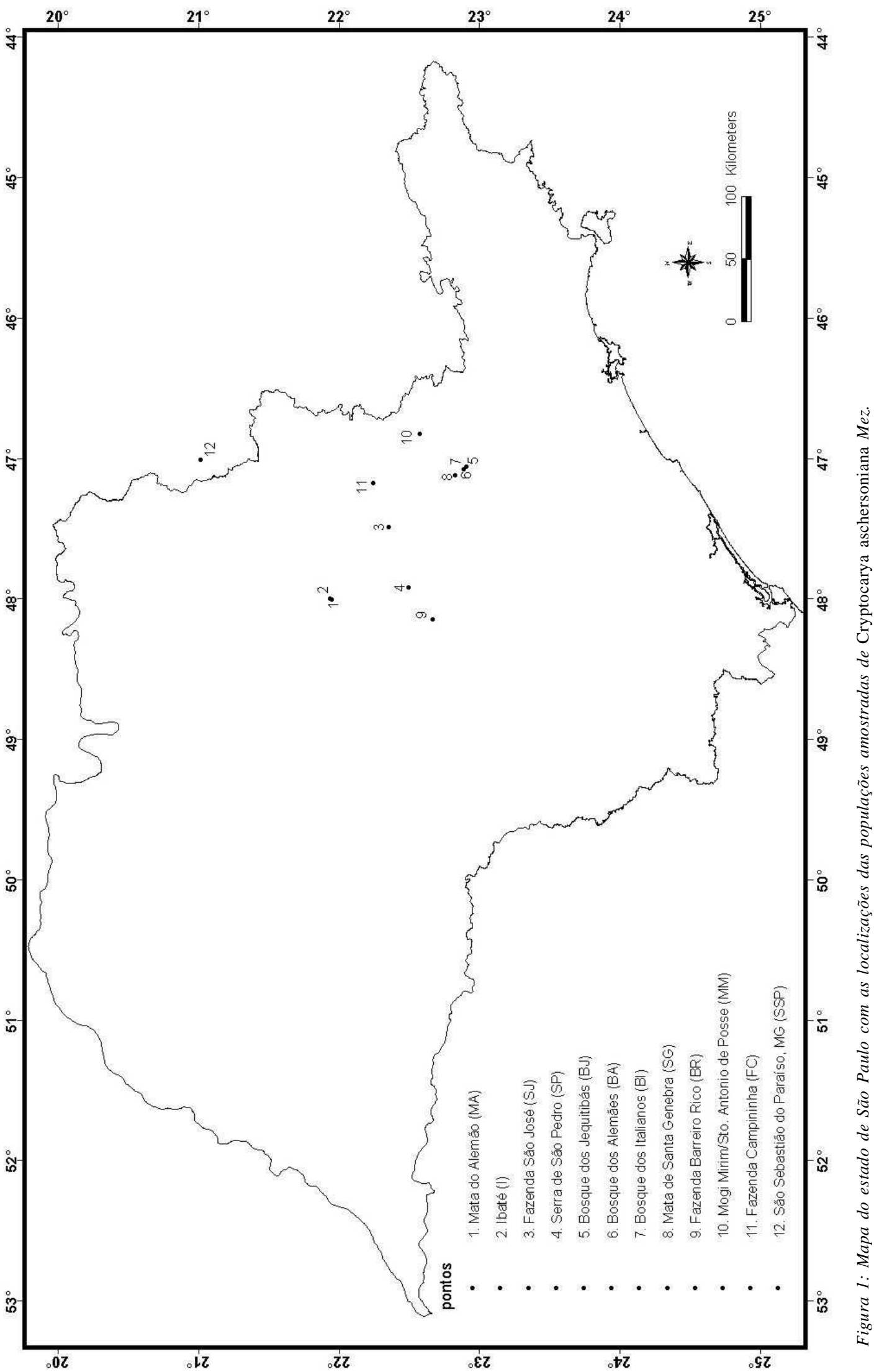

http://www.biotaneotropica.org.br 


\begin{tabular}{|c|c|c|}
\hline Braima & Código & Método de colaraça \\
\hline$\alpha$-Esterase & Alfa-EST - E.C.3.1.1.1 & Stuber et al (1988) \\
\hline $\begin{array}{l}\text { B-Esterase } \\
\text { Catakse }\end{array}$ & $\begin{array}{l}\text { Beta-EST - E.C 3.1.1.1 } \\
\text { CAT - E.C.1.11.1.6 }\end{array}$ & $\begin{array}{l}\text { Stuber et al }(1988)^{2} \\
\text { Scandalios }(1965)^{3} ; \\
\text { Afenas et al }(1991)^{2}\end{array}$ \\
\hline Diaf ase & DIA - E.C.18.1.4 & Afenas et al (1991) \\
\hline Fosfatase Ácida & ACP - E.C 3.1 .32 & Arenas et al (1991) \\
\hline $\begin{array}{l}\text { Fosfatase Alcalina } \\
\text { 6-Fofoghucanato Desidrogenase }\end{array}$ & $\begin{array}{l}\text { ALP - E.C.3.1.3.1 } \\
6 \mathrm{P} \text { GDH - E.C.1.1.1.44 }\end{array}$ & $\begin{array}{l}\text { Boyer }(1961)^{\mathbf{b}} \\
\text { Afrenas et al (1991) }\end{array}$ \\
\hline Fosfoghucose Isomerase & PGI - E.C.5.3.1.9 & Afenas etal (1991) \\
\hline Ghitamato Desidrogenase & GDH - E.C.1.4.13 & Afrenas etal (1991)² \\
\hline Ghitamato 0xabacetato Transaminase & GOT - E.C2 6.1 .1 & Brewbaker et al. (1968) \\
\hline Isocinato D esidrogenase & DH-E.C.1.1.1.42 (NADP') & Arenas etal $(1991)^{c}$ \\
\hline Malato Desidrogenase & $\mathrm{MDH}-$ E.C.1.1.1.37 & Arenas et al $(1991)^{c}$ \\
\hline Nicotinamida Aderina Dinucleotídeo Desiurogenase & FAD HDH - E.C.1.6.99.3 & AFenas et al (1991) \\
\hline $\begin{array}{l}\text { Hicotinamida Aderina Diracle dideo Fosfato } \\
\text { Desidrogenase }\end{array}$ & HAD PHDH - E.C.1.699.1 & AFenas et al (1991) \\
\hline Peroxidase & P0-E.C.1.11.1.7 & Brewbaker et al. (1968) \\
\hline Polifenoloxidase & PPO - E.C.1.103.1 & Afenas etal (1991) \\
\hline Syeróxido D iomutase & SOD - E.C.1.15.1.1 & Arenas et al (1991) \\
\hline Xigumato Desidrogenase & SKDH - E.C.1.1.1.25 & Arenas et al (1991)' \\
\hline
\end{tabular}

a tampão Lítio-Borato (LB): tampão do eletrodo: Tampão A (Lítio-Borato 0,24 M, Scandalios 1969): ác. bórico 0,19 M, titulado com Hidróxido de Lítio 0,05 M até pH 8,3; tampão do gel: Tampão B (Tris-cítrico 0,059 M, Scandalios 1969): ác. cítrico $0,008 \mathrm{M}$, titulado com Tris 0,051 M até pH 8,3. Mistura dos tampões A e B na proporção 1:9. Corrida eletroforética estabelecida em voltagem constante fixada em $300 \mathrm{~V}$, por 18 horas; $^{\mathbf{b}}{ }^{\mathbf{b}}$ tampão Tris-Citrato (TC): tampão do eletrodo: Tris 0,223 M + Ác. Cítrico 0,086 M, pH 7,5; tampão do gel: diluição a 7\% do tampão do eletrodo (Soltis et al. 1983). Voltagem constante fixada em $130 \mathrm{~V}$, por 19 horas; ${ }^{\mathrm{c}}$ tampão Citrato-Morfolina (CM): tampão do eletrodo: Ác. cítrico 0,04 M, titulado com N-(3-aminopropil) morfolina para o pH 6,1; tampão do gel: diluição a 1:20 do tampão do eletrodo (Clayton \& Tretiak 1972). Corrente constante fixada em $18 \mathrm{~mA}$, por 21 horas.

Tabela 2: Sistemas isoenzimáticos utilizados para as análises populacionais de Cryptocarya aschersoniana Mez, com indicação dos sistemas-tampão gel/eletrodo. 


\subsection{Análise de Dados}

A partir da interpretação dos zimogramas e conseqüente definição dos genótipos de cada indivíduo estudado, para os marcadores empregados, calcularam-se as frequiências alélicas para cada população amostrada, bem como as principais medidas de variabilidade genética, caracterizadas por: $\mathrm{A}$ = número médio de alelos por loco, obtido a partir da média aritmética do número de alelos de cada loco, em cada população, para cada loco, fazendo-se a média aritmética entre locos; $\mathrm{A}_{\mathrm{e}}=$ número efetivo de alelos, calculado de acordo com Crow \& Kimura (1970); P = proporção de locos polimórficos por população, obtida pela divisão do número de locos polimórficos (frequiência do alelo mais comum $<0,95)$ pelo número total de locos analisados. A heterozigosidade média observada $\left(\mathrm{H}_{\mathrm{o}}\right)$ foi obtida pela média aritmética das proporções do número total de heterozigotos em relação ao número total de indivíduos entre os locos analisados. A heterozigosidade esperada $\left(\mathrm{H}_{\mathrm{e}}\right)$ não viesada foi calculada por $\hat{H}_{\mathrm{e}}=2 \mathrm{n}\left(1-\sum \hat{\mathrm{x}}_{\mathrm{i}}^{2}\right) /(2 \mathrm{n}-1)$ (Nei 1978), com $\mathrm{n}=$ número de indivíduos amostrados, $\hat{\mathrm{X}}_{\mathrm{i}}=$ a freqüência populacional do i-ésimo alelo de um loco, fazendo-se a média aritmética entre os locos estudados.

Com base nas estimativas das freqüências observadas ( $\hat{\mathrm{H}}_{\mathrm{o}}$ ) e esperadas $\left(\hat{\mathrm{H}}_{\mathrm{e}}\right)$ de heterozigotos, calculou-se o índice de fixação ou coeficiente de endogamia $F$ de Wright $\left(\hat{F}_{(\mathrm{IS})}\right)$ para a população, $\hat{F}_{(\mathrm{IS})}=\left(\hat{\mathrm{H}}_{\mathrm{e}}-\hat{\mathrm{H}}_{\mathrm{o}}\right) / \hat{\mathrm{H}}_{\mathrm{e}}$, que é definido como o total de heterozigose observada em relação à heterozigose esperada em cruzamentos ao acaso (Wright 1978).

Testes exatos para verificação da hipótese nula de aderência ao Equilíbrio de Hardy-Weinberg (EHW) foram conduzidos através do método Monte Carlo, conforme apresentado por Guo \& Thompson (1992), através do programa TFPGA 1.3 (Miller 1997).

Para cada alelo identificado, foram computados os valores das estatísticas $F$ de Wright, a partir de seus estimadores não viesados $\left(F=F_{\mathrm{IT}}, \theta_{\mathrm{P}}=F_{\mathrm{ST}}\right.$ e $f=F_{\mathrm{IS}}$; Cockerham \& Weir 1993), com os respectivos testes de permutação para verificar suas significâncias, através do programa FSTAT 2.9.3.2 (Goudet 1995, 2002). Os intervalos de confiança foram calculados através de procedimentos de reamostragem do tipo bootstrap sobre os locos, para a média dos mesmos, e através de jackknifing sobre as amostras, para cada loco.

Testou-se o modelo de isolamento pela distância, conforme Slatkin (1993), com a realização de um teste de Mantel (1967), conforme Manly (1985; ver também Sokal 1979, e Sokal \& Rohlf 1995), através do coeficiente de correlação de Pearson, empregando-se os programas GENEPOP 3.3 (Raymond \& Rousset 1995), FSTAT 2.9.3.2
(Goudet 1995, 2002) e GENETIX 4.02 (Belkhir et al. 1996-

2001), que calculam $\hat{\theta}_{\mathrm{p}}$ e o número de migrantes por geração $(\mathrm{Nm})$ entre pares de populações.

Para a estimativa indireta de $\mathrm{Nm}$, a quantidade de migrantes por geração, empregou-se o método de Crow \& Aoki (1984), para um modelo de ilhas, com: $F_{\mathrm{ST}}=1 /(4 \alpha N m+$ $1)$, onde $\alpha=[n /(n-1)]^{2}$ e $n$ é o número de subpopulações. Utilizou-se o estimador $\hat{\theta}_{\mathrm{P}}$ no lugar de $\hat{F}_{\mathrm{ST}}$, conforme demonstração de Cockerham \& Weir (1993), por ser este menos viesado. A partir da estimativa de $\mathrm{Nm}$, calculou-se o valor do tamanho de vizinhança, $N b$, conforme fórmula proposta por Slatkin \& Barton (1989), a saber: $N_{b}=2 \pi N m$ (Eguiarte et al. 1993).

O tamanho efetivo populacional foi obtido através dos componentes da variância, de acordo com a metodologia apresentada por Vencovsky (1997), resumida a seguir. Para o caso de uma única população, com ausência de estruturação genética, o tamanho efetivo de população foi calculado através de $\hat{N}_{\mathrm{e}}=\mathrm{N} /(1+\hat{f})$, com $\mathrm{N}$ sendo o número de plantas adultas e $\hat{f}$ o coeficiente de endogamia intrapopulacional. Para o caso de indivíduos de várias populações, em um modelo de infinitas populações (sem correção para tamanho finito de populações), o cálculo foi feito através de $\hat{N}_{\mathrm{e}}=0,5 /\left\{\hat{\theta}_{\mathrm{P}}\left[\left(1+\mathrm{C}_{\mathrm{p}}\right) / \mathrm{P}-(1 / \mathrm{N})\right]+(1+\hat{F}) / 2 \mathrm{~N}\right\}$, onde $\hat{\theta}_{\mathrm{P}}$ é o coeficiente de coancestralidade relativo a populações, $\hat{F}$ é coeficiente médio de endogamia de todas as plantas nas populações analisadas, $\mathrm{N}$ é o número de indivíduos amostrados nas $\mathrm{P}$ populações; $\mathrm{N}=\Sigma \mathrm{N}_{\mathrm{i}} ; \mathrm{i}=1$, 2...P, e $\mathrm{C}_{\mathrm{p}}$ é o quadrado do coeficiente de variação do número de indivíduos $\left(\mathrm{N}_{\mathrm{i}}\right)$ entre as populações. 


\section{Resultados}

Os principais índices de diversidade gênica, bem como as heterozigosidades observadas e esperadas são apresentados na tabela 3 . As populações de $C$. aschersoniana apresentaram índices de diversidade gênica elevados, similares aos encontrados para outras espécies arbóreas tropicais. A população SP foi a que apresentou um maior excesso significativo de heterozigotos para o conjunto de locos polimórficos. Por outro lado, as populações BR, BI, FC, MA, MM e SSP, apresentaram endogamias intrapopulacionais altamente significativas. As populações BA, BJ, I, SG e SJ, por sua vez, mostraram-se dentro das proporções de EHW. O índice de fixação total para as 12 populações agrupadas e consideradas como uma única população mostrou-se altamente significativo, indicando déficit de heterozigotos.

Uma outra forma de se avaliar e visualizar a aderência dos locos às proporções esperadas de EHW pode ser observada pelo exame da figura 2 , em que são apresentadas as estimativas médias de $f\left(F_{\text {IS }}\right)$ por locos isoenzimáticos, a partir das 12 populações naturais de Cryptocarya aschersoniana. Apreende-se que 20 locos $(51,28 \%)$ apresentaram desvios positivos significativos (déficit de heterozigotos, endogamia) em relação às proporções de EHW, enquanto que oito $(20,51 \%)$ apresentaram desvios negativos significativos (excesso de heterozigotos, impedimento sistemático de cruzamentos endogâmicos) e $11 \operatorname{locos}(28,21 \%)$ apresentaram-se em equilíbrio (cruzamentos aleatórios).

Na figura 3, com as estimativas médias de $\theta_{\mathrm{P}}\left(F_{\mathrm{ST}}\right)$ para as 12 populações de $C$. aschersoniana, observa-se que a totalidade dos locos (39) apresentou-se significativamente positiva.

Pela análise da figura 4, dos valores médios de $F\left(F_{\mathrm{IT}}\right)$ para as populações de $C$. aschersoniana, observa-se que $28 \operatorname{locos}(71,8 \%)$ apresentaram valores de $F_{\text {IT }}$ significativamente positivos, indicando subdivisão sistemática ou em grupos autofecundados, enquanto que cinco $(12,8 \%)$ apresentaram valores significativamente negativos, indicando pouca ou nenhuma subdivisão sistemática e impedimento de cruzamentos endogâmicos, e seis locos $(15,4 \%)$ com valores não significativamente diferentes de zero.

Os valores de $\hat{\theta}_{\mathrm{P}}$ calculados entre os pares de populações encontram-se na tabela 4, todos significativamente diferentes de zero. Apreende-se que muitos valores de $\hat{\theta}_{\mathrm{P}}$ mostraram-se discrepantes em relação ao que poderia ser esperado a partir das distâncias geográficas entre os pares de populações.

Para se testar o modelo de isolamento pela distância, fez-se o teste não paramétrico de comparação de duas matrizes de distâncias. Para as populações de $C$. aschersoniana, o valor obtido para o Coeficiente de Mantel (Z) entre as matrizes dos logaritmos das distâncias geográficas e do número de migrantes por geração $(\mathrm{Nm})$ foi $-76,23$ com uma probabilidade $\mathrm{P}=0,8248$, a partir de 10.000 permutações. Então, não foi verificado o isolamento pela distância entre as populações analisadas de $C$. aschersoniana. Da mesma maneira, pelo gráfico também em escala logarítmica de $\hat{N} m$ versus a distância geográfica (figura 5), esperar-se-ia uma regressão aproximadamente linear em uma população em equilíbrio e com dispersão restrita. No entanto, o coeficiente de regressão foi de $-0,051$, com o coeficiente de determinação explicando apenas $2,24 \%$ da variância total de $\log (\hat{N} m)$, pela regressão.

A estimativa do número de migrantes por geração, calculado pelo método de Crow \& Aoki (1984), por ser indicado para o caso de poucas subpopulações, resultou num $\hat{N} m$ de 0,42 , com um tamanho de vizinhança $\left(\hat{N}_{b}\right)$ de 2,6 indivíduos, a partir da fórmula para um modelo de alpondras (Slatkin \& Barton 1989).

$\mathrm{Na}$ tabela 5, apreende-se que sob um contexto intrapopulacional, para a amostragem dos indivíduos de $C$. aschersoniana de São Pedro, os 17 indivíduos amostrados corresponderam a $\mathrm{Ne}$ de 21,09 indivíduos. De forma semelhante, os tamanhos efetivos encontrados para as amostragens das demais populações indicaram que houve uma adequada representatividade genética das amostras obtidas, a partir das freqüências alélicas dos locos analisados.

No entanto, sob um contexto metapopulacional, considerando-se as 12 populações amostradas para a espécie (populações como unidades amostrais), assumindo que a mesma fosse composta por infinitas populações, o tamanho efetivo populacional resultante foi de 15,4 indivíduos, para os 267 amostrados. Para o limite, $\operatorname{com~} \mathrm{C}_{\mathrm{P}}=$ 0 e $\mathrm{N}$ suficientemente grande, $N_{e} \rightarrow(0,5 \mathrm{P}) / \theta$, sendo igual a 17,91 indivíduos. 


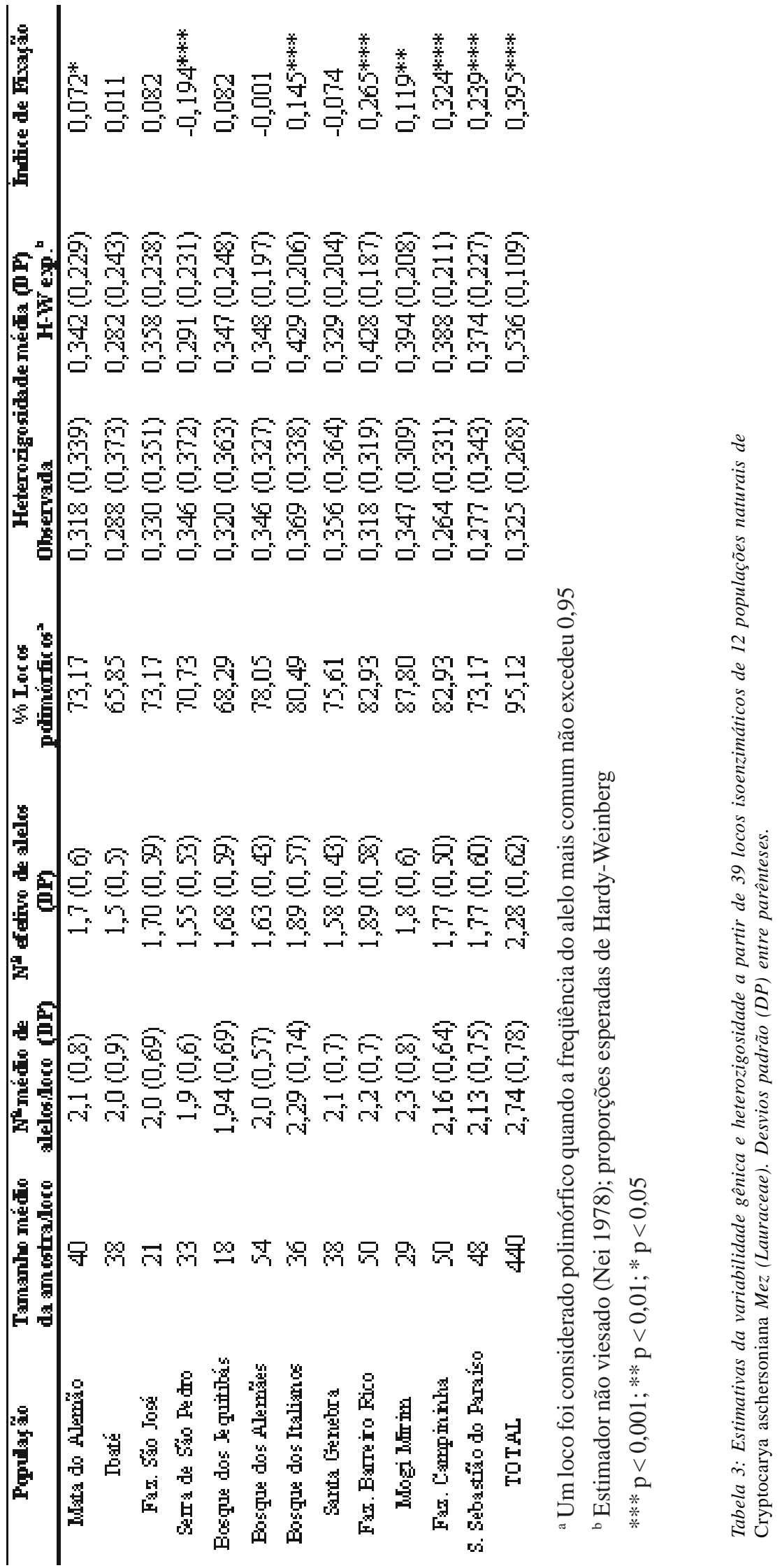




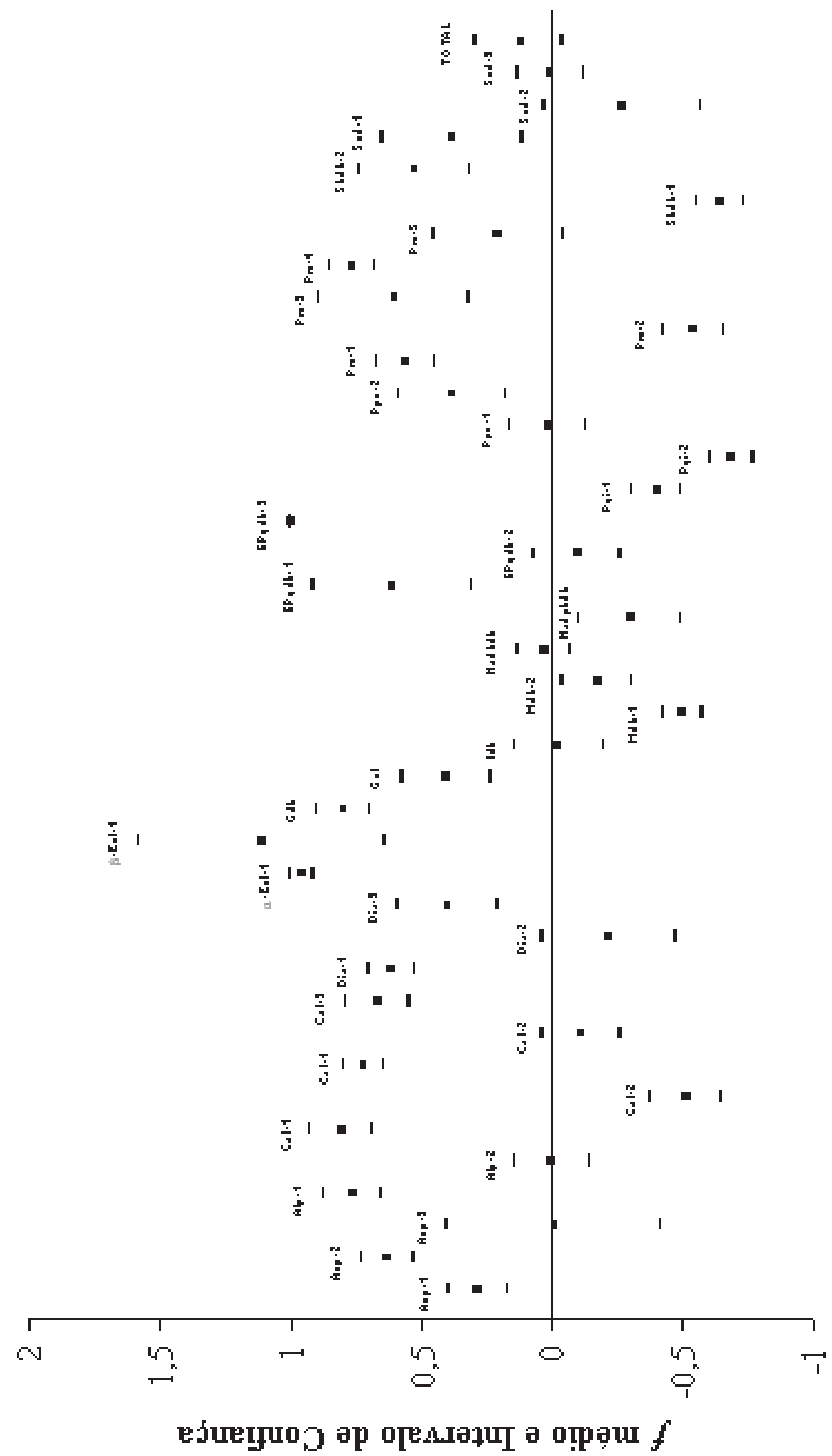




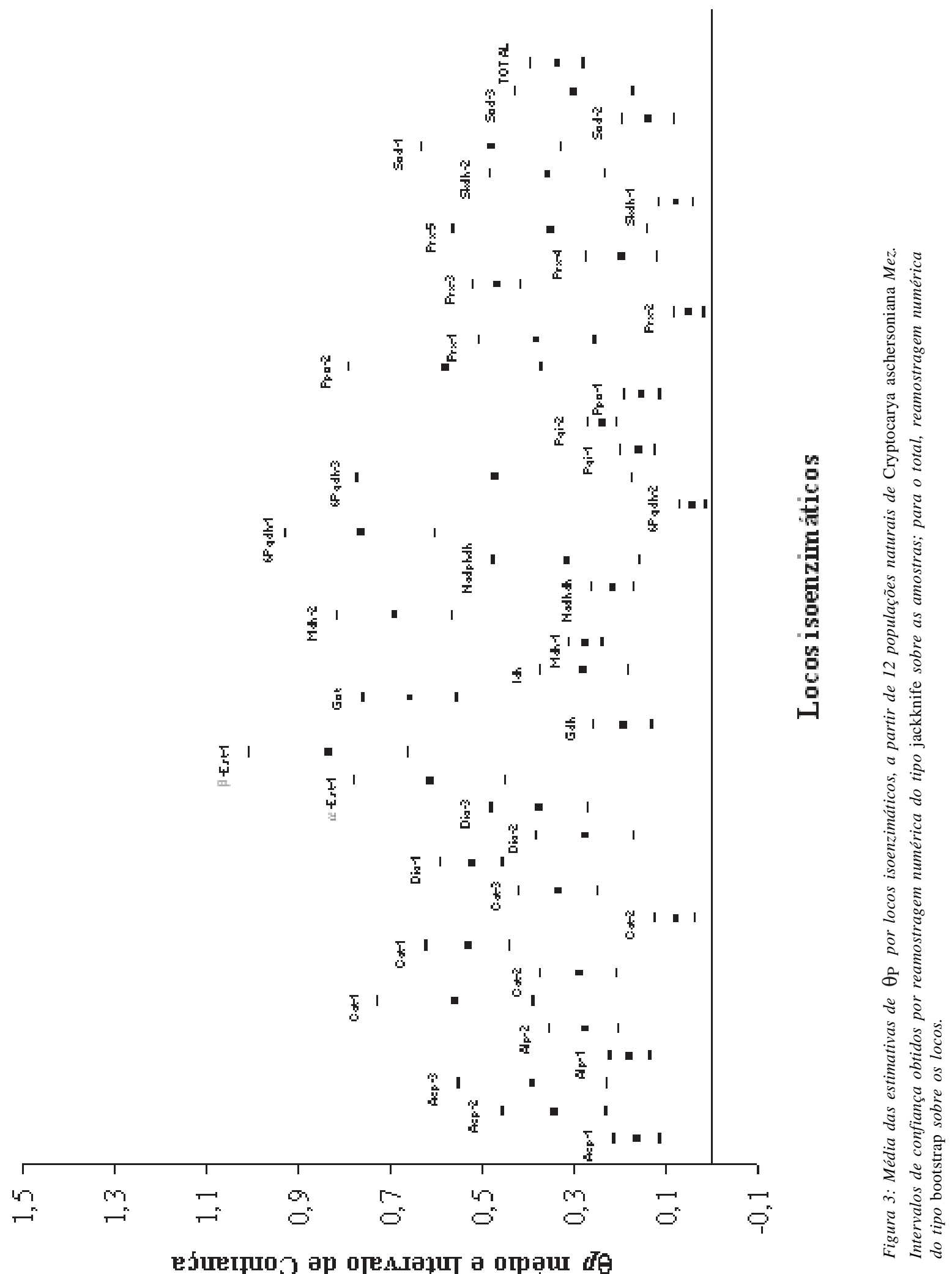



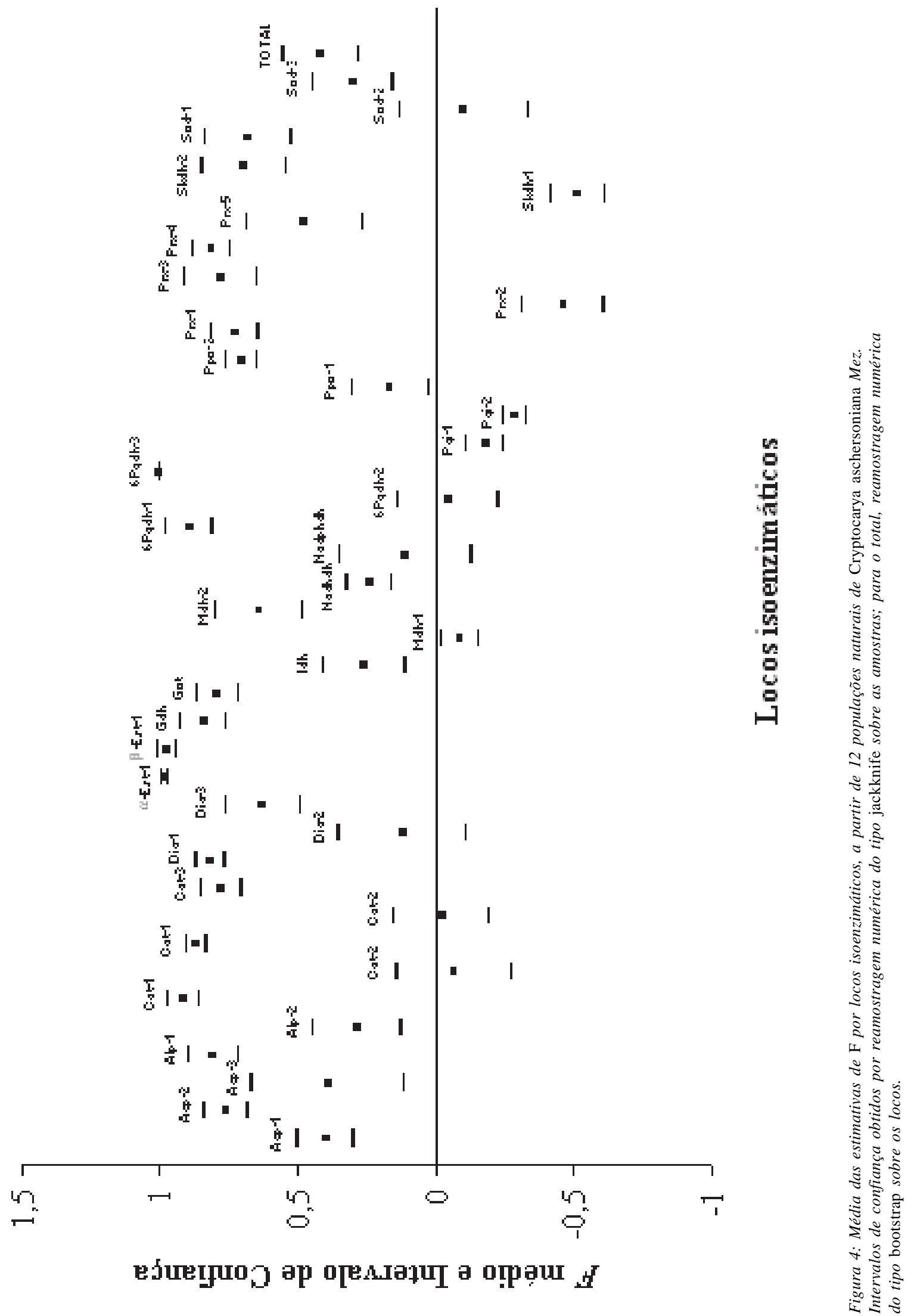


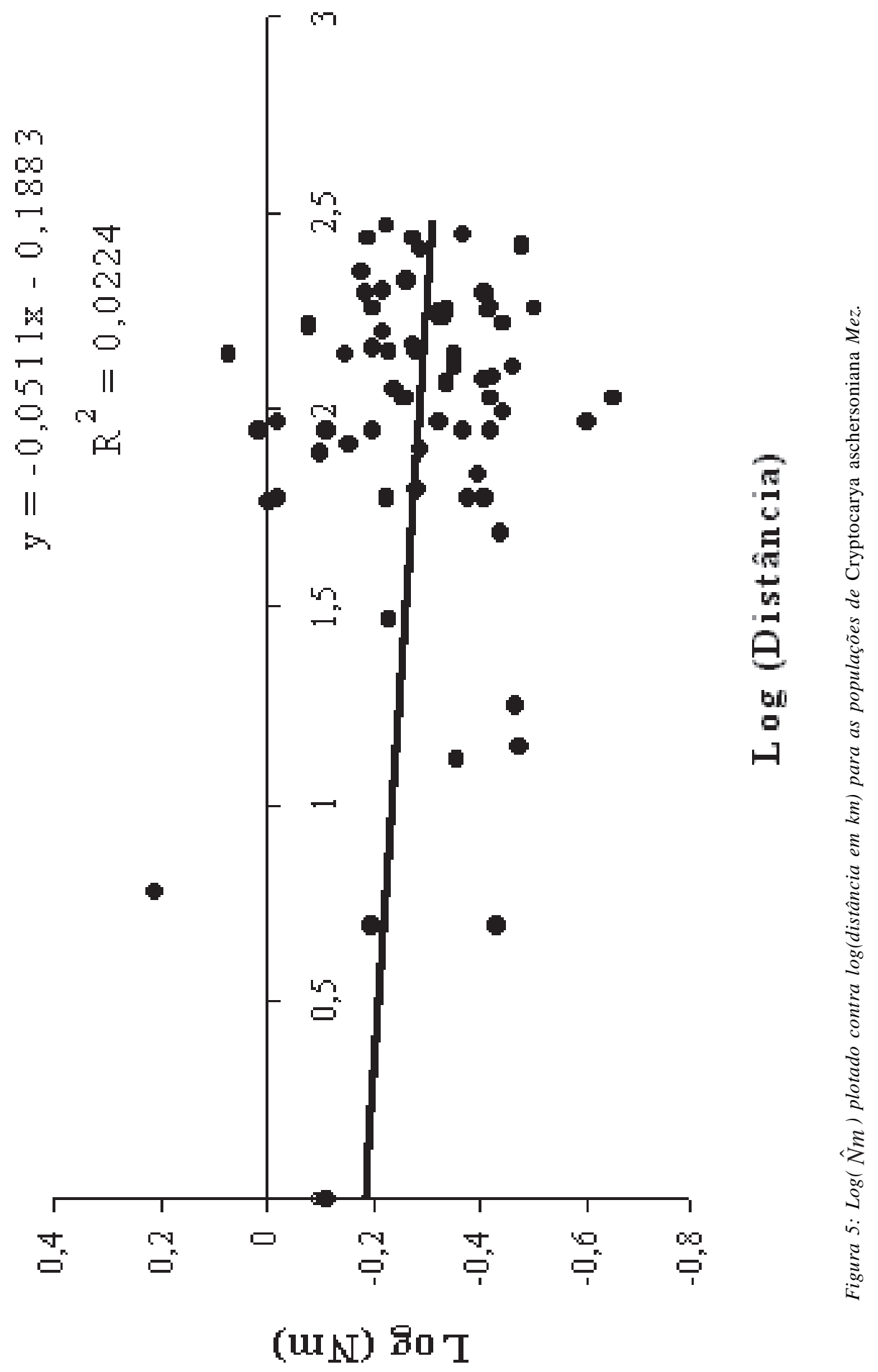

http://www.biotaneotropica.org.br 


\begin{tabular}{l|cccccccccccc}
\hline & MA & I & SI & SP & BJ & BA & BI & SG & BR & MMM & FC & SSP \\
\hline MA & & 0,281 & 0,209 & 0,410 & 0,399 & 0,356 & 0,286 & 0,347 & 0,304 & 0,232 & 0,286 & 0,293 \\
I & 0,54 & & 0,285 & 0,499 & 0,445 & 0,394 & 0,351 & 0,410 & 0,398 & 0,293 & 0,359 & 0,392 \\
SI & 0,44 & 0,63 & & 0,409 & 0,345 & 0,369 & 0,246 & 0,400 & 0,312 & 0,197 & 0,209 & 0,317 \\
SP & 0,36 & 0,25 & 0,36 & & 0,402 & 0,392 & 0,354 & 0,529 & 0,375 & 0,420 & 0,362 & 0,327 \\
BJ & 0,38 & 0,31 & 0,47 & 0,37 & & 0,404 & 0,133 & 0,423 & 0,323 & 0,324 & 0,263 & 0,370 \\
BA & 0,45 & 0,38 & 0,43 & 0,39 & 0,37 & & 0,246 & 0,429 & 0,323 & 0,295 & 0,327 & 0,321 \\
BI & 0,52 & 0,46 & 0,77 & 0,46 & 1,62 & 0,77 & & 0,364 & 0,298 & 0,202 & 0,242 & 0,280 \\
SG & 0,47 & 0,36 & 0,38 & 0,22 & 0,34 & 0,33 & 0,44 & & 0,175 & 0,391 & 0,386 & 0,430 \\
BR & 0,57 & 0,38 & 0,55 & 0,42 & 0,52 & 0,52 & 0,59 & 1,18 & & 0,347 & 0,260 & 0,296 \\
MMM & 0,83 & 0,60 & 1,02 & 0,34 & 0,52 & 0,50 & 0,98 & 0,39 & 0,47 & & 0,298 & 0,275 \\
FC & 0,52 & 0,45 & 0,94 & 0,44 & 0,70 & 0,51 & 0,78 & 0,40 & 0,71 & 0,59 & & 0,777 \\
SSP & 0,50 & 0,39 & 0,54 & 0,51 & 0,43 & 0,53 & 0,64 & 0,33 & 0,59 & 0,56 & 0,65 & \\
\hline
\end{tabular}

Tabela 4: Matriz das estimativas de $\theta_{P}$ (diagonal superior) e de $\mathrm{N}_{m}$ (diagonal inferior) para 12 populações de Cryptocarya aschersoniana $\mathrm{Mez}$

\begin{tabular}{|c|c|c|c|}
\hline Pop ukação & $\mathbf{N}$ & $f=F_{\text {IS }}$ & $N_{*}^{2}$ \\
\hline Mata do Ale rtão & 26 & 0,072 & 24,25 \\
\hline Tbaté & 25 & 0,011 & 24,73 \\
\hline Fazenda São José & 12 & 0,082 & 11,09 \\
\hline Serra de São Pedro & 17 & $-0,194$ & 21,09 \\
\hline Bosque dos Jequitbás & 10 & 0,082 & 9,24 \\
\hline Bosque dos Alemães & 30 & $-0,002$ & 30,06 \\
\hline Bosque dos Italianos & 20 & 0,145 & 17,47 \\
\hline Santa Ge rebra & 20 & $-0,074$ & 21,60 \\
\hline Barre iro Rico & 29 & 0,265 & 22,92 \\
\hline Mogi Mrim & 16 & 0,120 & 14,29 \\
\hline Fazenda Carquininta & 32 & 0,324 & 24,17 \\
\hline São Sebastã̃o do Paraío & 30 & 0,267 & 23,68 \\
\hline TOTAL & 267 & 0,119 & $15,40^{\mathrm{b}}$ \\
\hline
\end{tabular}

a para uma população sem estrutura genética: $\hat{N}_{\mathrm{e}}=\mathrm{N} /(1+\hat{f}) ;{ }^{\mathrm{b}}$ para muitas populações em um modelo de infinitas populações: $\hat{\mathrm{N}}_{e}=0,5 / / \hat{\boldsymbol{\theta}}_{P}{ }^{[(1+} C_{p}{ }^{/ P-(1 / N)]+(1+\hat{\mathrm{F}}) / 2 N\}},($ Vencovsky 1997) 


\section{Discussão}

Os resultados dos índices de diversidade gênica e das heterozigosidades, apresentados na tabela 3 , sugeriram a existência de diferenças entre as populações em relação às freqüências alélicas e níveis de diversidade, indicando uma divergência entre as mesmas. Adicionalmente, esses valores foram similares aos encontrados para outras espécies de Angiospermas arbóreas tropicais.

Os resultados das estimativas médias de $\theta_{\mathrm{P}}$ (figura 3) indicaram, também, haver uma divergência altamente significativa entre as populações analisadas, que poderia ser decorrente do efeito de Wahlund. As diferenças significativas das freqüências alélicas entre as subpopulações podem dar a "aparência estatística" de uma deficiência de heterozigotos para a população inteira (Hartl \& Clark 1989). O efeito de Wahlund poderia ser, nesse caso, um erro de amostragem causado quando as subpopulações fossem estabelecidas a partir de fundadores com freqüências alélicas diferentes das outras subpopulações ou da população como um todo. A diferenciação populacional encontrada para $C$. aschersoniana mostrou-se superior aos valores encontrados para outras espécies arbóreas tropicais. A ausência de valores negativos encontrados para os coeficientes de coancestralidade indicou que, provavelmente, as freqüências alélicas dos indivíduos se adequaram ao modelo aleatório de Cockerham, sugerindo que as isoenzimas utilizadas como marcadores no presente trabalho seriam totalmente neutras. Isso ocorre porque o modelo de Cockerham assume que as divergências nas frequiências alélicas são resultantes exclusivamente de deriva genética, não pressupondo a existência de qualquer seleção (Weir 1996).

De acordo com Nei (1987), vários são os fatores que podem levar a um valor de $F$ diferente de zero, sendo que a endogamia, cruzamentos preferenciais, subdivisão populacional e seleção seriam os mais importantes. Quando a endogamia é o único fator responsável pelo aumento da freqüência de homozigotos, $F$ é igual ao coeficiente de endogamia de Wright (1969), com um valor sempre positivo. Para os organismos com sistema misto de cruzamento, quando a probabilidade de exocruzamento é $t$, o valor de equilíbrio de $F$ é $(1-t) /(1+t)$. Um outro tipo de reprodução não aleatória é o dos cruzamentos preferenciais, que ocorrem entre indivíduos que compartilham caracteres fenotípicos similares. Esse tipo de cruzamento tem um efeito semelhante ao da endogamia por também promover um aumento na frequiência de homozigotos. Porém, esse efeito se restringe apenas aos locos relacionados com o caráter para o qual os cruzamentos preferenciais ocorrem (Wright 1969). Para o caso de subdivisão populacional, existe uma dificuldade em se conhecer a estrutura reprodutiva de uma população, que pode incluir várias unidades reprodutivas ou subpopulações.
Nesse caso, mesmo que cada subpopulação apresente-se em EHW, as freqüências genotípicas da população inteira podem desviar das proporções esperadas. Essa propriedade foi notada inicialmente por Wahlund (1928) e é denominada por efeito ou princípio de Wahlund. Por sua vez, a seleção pode aumentar ou diminuir o valor de $F$, dependendo do tipo de seleção. Com isto, a predominância de cruzamentos não aleatórios para a maioria dos locos, no presente trabalho, poderia ser explicada pela existência de cruzamentos preferenciais.

Segundo Cockerham (1973), dentre os vários fatores que podem afetar essas correlações intraclasses, os principais seriam a endogamia, seleção, migração, fertilidade diferencial, cruzamentos preferenciais, diferenças nas freqüências gênicas de gametas masculinos e femininos e misturas de subdivisões. Para uma discussão sobre os efeitos desses fatores, seria necessária uma distinção entre aqueles que levam a uma diferenciação entre as subpopulações, daqueles que se relacionam com os processos ocorridos dentro das mesmas. Dessa forma, se os genes estiverem distribuídos aleatoriamente dentro das subpopulações, então as diferenças entre os mesmos contribuiriam igualmente para $F$ e $\theta_{\mathrm{P}}$ e não para $f$. Desta forma, $f$ seria quase que exclusivamente uma conseqüência dos efeitos dentro das subpopulações, estando relacionado ao sistema reprodutivo das mesmas. De maneira semelhante, os efeitos de seleção sobre os alelos de um loco também podem ter conseqüências sobre $f$, pois, a menos que a viabilidade dos heterozigotos seja menor ou igual à média geométrica das viabilidades dos homozigotos, levariam a um $f$ negativo (Wallace 1958; Lewontin \& Cockerham 1959; Workman 1969). As freqüências gênicas diferenciais para gametas masculinos e femininos podem produzir uma diminuição de homozigotos e um aumento de heterozigotos. Se houver uniões aleatórias de gametas, estas são independentes, porém, haverá um excesso de heterozigotos em relação às freqüências esperadas sob EHW (também independentes), quando as duas freqüências diferirem. Ainda, cruzamentos preferenciais teriam uma contribuição positiva sobre $f$, ao passo que os não preferenciais teriam uma contribuição negativa (Cockerham 1973).

Ainda, com relação à origem das discrepâncias encontradas nos resultados das estatísticas $F$ entre os diferentes locos, tem-se que o conhecimento do controle genético e do modo de herança dos padrões isoenzimáticos seria um pré-requisito para seu uso nas análises genéticas, uma vez que poderiam existir padrões de bandas que imitam a segregação Mendeliana dos genes, especialmente nas fosfatases, esterases e peroxidases (Sousa 2001). Com isto, de acordo com Chagala (1996), a falta de informação sobre a herança poderia levar a estimativas viesadas das freqüências alélicas e a uma hiperestimativa dos níveis de heterozigosidade. No presente trabalho, não foi possível a análise das progênies das populações amostradas, devido 
à baixa taxa de germinação dos diásporos coletados, mas houve, porém, a confrontação dos padrões de bandas obtidos para $C$. aschersoniana com aqueles encontrados por Moraes \& Monteiro (2002), em que se verificou a segregação dos locos isoenzimáticos através de progênies de C. moschata com suas respectivas árvores-mãe, para os sistemas ACP, ALP, CAT, GOT, PPO e PRX. A base genética para os demais sistemas foi interpretada a partir de homologias e analogias com outras plantas reportadas na literatura, aliadas ao conhecimento da estrutura quaternária existente para muitas delas. No entanto, em sistemas como DIA, MDH, PGI e SOD, em que se utilizou o procedimento mais parcimonioso ao se considerar o número total de locos monomórficos pela interpretação de cada banda fixada como um loco separado, tem-se que o número de locos monomórficos atribuídos a tais sistemas isoenzimáticos poderia também afetar fortemente os cálculos de variabilidade genética relativa, tais quais os de porcentagem de locos polimórficos e de heterozigosidade (Hall et al. 1994). Com isto, não se descarta a possibilidade de que para alguns dos locos avaliados tenha havido vieses nas estimativas das freqüências alélicas, devido à interpretação equivocada dos padrões de bandas apresentados.

Com relação ao modelo de fluxo gênico avaliado, pelo modelo de alpondras bidimensional (dispersão entre os vizinhos mais próximos), esperar-se-ia que populações que nunca trocam migrantes não deveriam exibir valores muito maiores do que as que trocam (Rousset 1997), como o encontrado para as populações BA e BI $\left(\theta_{\mathrm{P}}=0,246\right)$ e BA e $\mathrm{SG}\left(\boldsymbol{\theta}_{\mathrm{P}}=0,429\right)$, por exemplo. De forma semelhante, a partir de um modelo clássico de isolamento pela distância, seria esperado um aumento de $\hat{\theta}_{P}$ com o aumento da distância entre os pares (Raybould et al. 1995).

Os resultados do presente trabalho mostraram que o padrão obtido não indicou que a espécie apresente isolamento pela distância, estando em equilíbrio com migração e deriva. No entanto, uma ausência de um padrão de isolamento pela distância poderia também ocorrer devido a uma amostragem a grandes distâncias, uma vez que poderia haver dependência da amplitude dos (logaritmos dos) valores das distâncias investigadas, e da variância dos estimadores, que seriam provavelmente menores a curtas distâncias (Rousset 1997). Contudo, seria improvável a suposição de que com o atual estado de fragmentação das populações aqui investigadas, que já se encontram relativamente isoladas há algumas gerações, pudessem ainda apresentar fluxo gênico significativo através de polinizadores de vôo curto e dispersão de diásporos por grandes primatas e cracídeos, que seriam os principais vetores dessa movimentação (vide Moraes et al. 1999). Os valores de $\theta_{\mathrm{P}}$ encontrados para os pares de populações indicariam, dessa forma, que fatores como deriva e efeitos de fundador poderiam estar provavelmente relacionados à alta divergência encontrada entre essas populações. Nesse sentido, os testes realizados para aderência ao Equilíbrio entre Mutação e Deriva genética (P.L.R. Moraes \& M.T.V.C. Derbyshire, dados não publicados), conforme metodologia descrita em Cornuet \& Luikart (1996), Luikart \& Cornuet (1998), e Piry et al. (1999), mostraram que nenhuma das populações de $C$. aschersoniana encontrou-se em equilíbrio, indicando ocorrência de bottlenecks.

Adicionalmente, os valores de $\mathrm{Nm}$ e $\mathrm{Nb}$ determinaram se a deriva genética, por si só, poderia produzir variabilidade genética substancial entre locais. Se $\mathrm{Nm}$ fosse maior que 1,0, o fluxo gênico seria alto o suficiente para prevenir uma diferenciação devida à deriva (Slatkin \& Barton 1989). Neste trabalho, o número médio de migrantes por geração $(\hat{N} m)$ foi pronunciadamente inferior a 1,0 , indicando que o fluxo gênico não seria suficiente para evitar uma diferenciação populacional devido à deriva genética, e podendo ser considerado relativamente baixo quando comparado aos valores obtidos de outras espécies de Angiospermas arbóreas tropicais. O número de genitores que trocariam genes ao acaso resultou em torno de 3 indivíduos, sendo que um número menor de indivíduos em uma mesma unidade de área implicaria em um aumento da divergência entre as vizinhanças. A partir dos valores estimados de $\mathrm{Nb}$, as áreas de vizinhança para cada uma das populações poderiam ser também estimadas caso houvessem informações sobre as respectivas densidades populacionais, obtendo-se posteriormente uma média para a espécie, a partir das mesmas (vide Moraes et al. 1999).

A avaliação da representatividade genética das amostras foi feita através do tamanho efetivo populacional, $\mathrm{Ne}$, que seria um parâmetro crucial para o julgamento do impacto da deriva sobre a estrutura genética de populações. $\mathrm{O}$ entendimento da relação entre o tamanho efetivo e o tamanho real de uma população de plantas seria fundamental para um planejamento de conservação porque uma grande diferença entre $\mathrm{N}$ e $\mathrm{Ne}$ poderia iludir os pesquisadores quanto ao status de uma espécie. Em essência, essa relação dependeria basicamente da variabilidade entre os indivíduos ao longo do tempo de seu sucesso reprodutivo, combinando tanto variáveis populacionais ecológicas quanto as genéticas (Moraes et al. 1999). Para o presente trabalho, observou-se a partir da formulação $\hat{N}_{\mathrm{e}}=\mathrm{N} /(1+\hat{f})$ que a endogamia reduziu o tamanho efetivo populacional, e os valores insignificantes encontrados de $\hat{f}$ fizeram com que os de $\hat{N}_{e}$ fossem praticamente iguais aos números de indivíduos amostrados. Por sua vez, apreendeu-se que a amostragem realizada para a espécie correspondeu a 85,98\% do tamanho efetivo máximo obtido a partir de 12 populações com um $\hat{\boldsymbol{\theta}}_{P}$ de 0,335 , correspondendo a apenas $5,77 \%$ dos indivíduos amostrados. Ficou evidente que o tamanho efetivo obtido para a espécie foi bastante pequeno, visto que a divergência entre as populações foi relativamente elevada, indicando que a amostragem de diferentes 
populações seria uma estratégia importante, mesmo quando a divergência entre elas fosse relativamente pequena, conforme apontado por Vencovsky (1997) e analisado para populações de C. moschata por Moraes et al. (1999).

Pelo exposto, caberia ressaltar que as populações de C. aschersoniana de fragmentos florestais pequenos e perturbados como os dos Bosque dos Alemães e Bosque dos Italianos apresentaram uma diversidade genética tão alta como a de fragmentos maiores como da Mata de Santa Genebra e da Fazenda Barreiro Rico. Adicionalmente, considerando-se também que a divergência genética foi relativamente alta entre as populações estudadas, os dados obtidos poderiam ser úteis no suporte à preservação de pequenos fragmentos, mesmo que urbanos e muito perturbados.

\section{Agradecimentos}

Ao Instituto de Botânica, Prefeitura Municipal de Campinas, Fundação José Pedro de Oliveira, Sr. José Carlos Reis de Magalhães, Sr. Djalma Brasil Zabeu, pelas respectivas autorizações de coleta na Fazenda Campininha, nos "Bosques" do município, na Mata de Santa Genebra, na Fazenda Barreiro Rico, e na Fazenda Palmital. Ao Marco Aurélio Nalon pela feitura do mapa de localização das áreas estudadas. Ao Angelo Gilberto Manzatto e Antonio Carlos Scutti, pela logística e auxílio nas coletas na Fazenda São José e na região do sul de Minas Gerais, respectivamente. Aos estagiários Mariana Campanholi Daher e Fernando Henrique Romano, pelo auxílio nas análises laboratoriais. Às críticas e sugestões de dois referees anônimos que em muito contribuíram para o aprimoramento do manuscrito.

\section{Referências bibliográficas}

ALFENAS, A.C., PETERS, I., BRUNE, W. \& PASSADOR, G.C. 1991. Eletroforese de proteínas e isoenzimas de fungos e essências florestais. Universidade Federal de Viçosa, Impr. Univ., Viçosa.

ASSUMPÇÃO, C.T., LEITÃO FILHO, H.F. \& CESAR, O. 1982. Descrição das matas da Fazenda Barreiro Rico, estado de São Paulo. Rev. Bras. Bot. 5:53-66.

BELKHIR, K., BORSA, P., CHIKHI, L., RAUFASTE N. \& BONHOMME, F. 1996-2001 GENETIX 4.02, logiciel sous Windows ${ }^{\mathrm{TM}}$ pour la génétique des populations. Laboratoire Génome, Populations, Interactions, CNRS UMR 5000, Université de Montpellier II, Montpellier (France). (www.univ-montp2.fr/ genetix/genetix.htm)

BOYER, S.H. 1961. Alkaline phosphatase in human sera and placentae. Science 134:1002-1004.
BREWBAKER, J.L, UPADHYA, M.D., MAKINEN, Y. \& MACDONALD, T. 1968. Isoenzyme polymorphism in flowering plants, III. Gel electrophoretic methods and applications. Physiol. Plant. 21:930-940.

BROWN, A.H.D. 1979. Enzyme polymorphism in plant populations. Theor. Pop. Biol. 15:1-42.

BUCKLEY,D.P., O’MALLEY,D.M., APSIT, V., PRANCE, G.T. \& BAWA, K.S. 1988. Genetics of Brazil nut (Bertholletia excelsa Humb. \& Bonpl.: Lecythidaceae). 1. Genetic variation in natural populations. Theor. Appl. Genet. 76:923-928.

CESAR, O. \& LEITÃO FILHO, H.F. 1990. Estudo florístico quantitativo de mata mesófila semidecídua na Fazenda Barreiro Rico, município de Anhembi, SP. Rev. Bras. Biol. 50:133-147.

CHAGALA, E.M. 1996. Inheritance and linkage of allozymes in Pinus strobus L. Silvae Gen. 45:181-187.

CLAYTON, J.W. \& TRETIAK, D.N. 1972. Amine-citrate buffers for $\mathrm{pH}$ control in starch gel electrophoresis. J. Fish. Res. Board Can. 29:1169-1172.

COCKERHAM, C.C. 1973. Analyses of gene frequencies. Genetics 74:679-700.

COCKERHAM, C.C. \& WEIR, B.S. 1993. Estimation of gene flow from $F$-statistics. Evolution 47:855-863.

CORNUET, J.-M. \& LUIKART, G. 1996. Description and power analysis of two tests for detecting recent population bottlenecks from allele frequency data. Genetics 144:2001-2014.

CROW, J.F. \& AOKI, K. 1984. Group selection for polygenic behavioral trait: estimating the degree of population subdivision. Proc. Natl. Acad. Sci. U.S.A. 81:6073-6077.

CROW, J.F. \& KIMURA, M. 1970. An introduction to population genetics theory. Harper \& Row, New York.

EGUIARTE, L.E., BURQUEZ, A., RODRÍGUEZ, J., MARTÍNEZ-RAMOS, M., SARUKHÁN, J. \& PIÑERO, D. 1993. Direct and indirect estimates of neighborhood and effective population size in a tropical palm, Astrocaryum mexicanum. Evolution 47:75-87.

GOTTLIEB, L.D. 1977. Electrophoretic evidence and plant systematics. Ann. MO Bot. Gard. 64:161-180.

GOUDET, J. 1995. FSTAT (version 1.2): a computer program to calculate $F$-statistics. J. Hered. 86:485-486.

GOUDET, J. 2002. FSTAT, a program to estimate and test gene diversities and fixation indices (version 2.9.3.2). Available from http://www.unil.ch/izea/softwares/ fstat.html. Updated from Goudet (1995).

GUO, S.W. \& THOMPSON, E.A. 1992. Performing the exact test of Hardy-Weinberg proportion for multiple alleles. Biometrics 48:361 372. 
HALL, P., ORRELL, L.C. \& BAWA, K.S. 1994. Genetic diversity and mating system in a tropical tree, Carapa guianensis (Meliaceae). Am. J. Bot. 81:1104-1111.

HAMRICK, J.L. \& GODT, M.J. 1990. Allozyme diversity in plant species. In Population genetics, breeding and germplasm resources in crop improvement (A.H.D. Brown, M.T. Clegg, A.L. Kahler \& B.S. Weir, eds.). Sinauer, Sunderland, MA, p. 43-63.

HAMRICK, J.L., LINHART, Y.B. \& MITTON, J.B. 1979. Relationships between life history characteristics and eletrophoretically detectable genetic variation in plants. Ann. Rev. Ecol. Syst. 10:173-200.

HARTL, D.L. \& CLARK, A.G. 1989. Principles of population genetics. 2nd. ed. Sinauer Associates, Sunderland.

JOLY, C.A., AIDAR, M.P.M., KLINK, C.A., McGRATH, D.G., MOREIRA, A. G., MOUTINHO, P., NEPSTAD, D.C., OLIVEIRA, A.A., POTT, A., RODAL, M.J.N. \& SAMPAIO, E.V.S.B. 1999. Evolution of the Brazilian phytogeography classification systems: implications for biodiversity conservation. Ciência e Cultura 51:331-348.

KOSTERMANS, A.J.G.H. 1937. Revision of the Lauraceae II. The genera Endlicheria, Cryptocarya (American species) and Licaria. Med. Bot. Mus. Herb. Rijk. Univ. Utrecht 42:500-609.

KOSTERMANS, A.J.G.H. 1938. Revision of the Lauraceae III. The genera Aiouea, Systemonodaphne, Urbanodendron, Mezilaurus; additions and corrections to Licaria and Cryptocarya. Recueil. Trav. Bot. Néerl. 35:56-129.

KOSTERMANS, A.J.G.H. 1957. Lauraceae. Reinwardtia 4:193-256.

LEWONTIN, R.C. \& COCKERHAM, C.C. 1959. The goodness-of-fit test for detecting natural selection in random mating populations. Evolution 13:561-564.

LUIKART, G. \& CORNUET, J.-M. 1998. Empirical evaluation of a test for identifying recently bottlenecked populations from allele frequency data. Conserv. Biol. 12:228237.

MANLY, B.F.J. 1985. The statistics of natural selection on animal populations. Chapman and Hall, London.

MANTEL, N. 1967. The detection of disease clustering and generalized regression approach. Cancer Res. 27:209-220.

MILLER, M.P. 1997. Tools for population genetic analyses (TFPGA) 1.3: a Windows program for the analysis of allozyme and molecular population genetic data. Computer software distributed by author.

MORAES, P.L.R. \& ALVES, M.C. 2002. Biometria de frutos e diásporos de Cryptocarya aschersoniana Mez e Cryptocarya moschata Nees (Lauraceae). Biota Neotropica 2(1). (www.biotaneotropica.org.br/v2n1/pt/ abstract?article+BN01302012002)
MORAES, P.L.R. \& MONTEIRO, R. 2002. Taxas de cruzamento em uma população natural de Cryptocarya moschata Nees (Lauraceae). Biota Neotropica 2(2). (www.biotaneotropica.org.br/v2n $2 / \mathrm{pt} /$ abstract?article+BN01102022002)

MORAES, P.L.R., MONTEIRO, R. \& VENCOVSKY, R. 1999. Conservação genética de populações de Cryptocarya moschata Nees (Lauraceae) na Mata Atlântica do estado de São Paulo. Rev. Bras. Bot. 22:237-248. ( $\mathrm{h}$ t t p : / / w w w. S c i e l o . b r / $\underline{\text { scielo.php? script }=\text { sci abstract } \& \text { pid }=S 0100-}$ $\underline{84041999000500004 \& \operatorname{lng}=\text { en\&nrm=iso) }}$

NASON, J.D., PRESTON, A.R. \& HAMRICK, J.L. 1997. Dispersal and dynamics of genetic structure in fragmented tropical tree populations. In Tropical forest remnants; ecology, management, and conservation of fragmented communities (W.F. Laurence \& R.O. Bierregaard, eds). The University of Chicago Press, Chicago, p.304-320.

NEI, M. 1978. Estimation of average heterozygosity and genetic distance from a small number of individuals. Genetics 89:583-590.

NEI, M. 1987. Molecular evolutionary genetics. Columbia University Press, New York.

NEVO, E. 1978. Genetic variation in natural populations: patterns and theory. Theor. Pop. Biol. 13:121-177.

PAGANO, S.N. \& LEITÃO FILHO, H.F. 1987. Composição florística do estrato arbóreo de mata mesófila semidecídua, no município de Rio Claro (Estado de São Paulo). Rev. Bras. Bot. 10:37-47.

PIRY, S., LUIKART, G. \& CORNUET, J.-M. 1999. BOTTLENECK: a computer program for detecting recent reductions in the effective population size using allele frequency data. J. Hered. 90:502-503.

RAYBOULD, A.F., GOUDET, J., MOGG, R.J., GLIDDON, C.J. \& GRAY, A.J. 1995. Genetic structure of a linear population of Beta vulgaris ssp. maritima (sea beet) revealed by isozyme and RFLP analysis. Heredity 76:111-117.

RAYMOND, M. \& ROUSSET, F. 1995. GENEPOP(Version 1.2): population genetics software for exact tests and ecumenicism. J. Hered. 86:248-249.

ROBINSON, I.P. 1998. Aloenzimas na genética de populações de plantas. In Eletroforese de isoenzimas e proteínas afins: fundamentos e aplicações em plantas e microrganismos (A.C. Alfenas, ed.). Editora UFV, Viçosa, p.329-380.

ROCHA, O.J. \& LOBO, J.A. 1998. Genetic diversity and outcrossing rates in the guanacaste tree (Enterolobium cyclocarpum Jacq.) in the dry forests of Costa Rica. In Recent Advances in Biotechnology for Tree Conservation and Management, Proceedings of an IFS Workshop. International Foundation for Science (IFS), Stockholm, p.65-81. 
ROUSSET, F. 1997. Genetic differentiation and estimation of gene flow from $F$-Statistics under isolation by distance. Genetics 145:1219-1228.

SCANDALIOS, J.G. 1965. Genetic isozyme variations in Zea mays. University of Hawaii, Honolulu. (PhD Thesis).

SCANDALIOS, J.G. 1969. Genetic control of multiple molecular forms of enzymes in plants. Biochem. Genet 3:3779

SLATKIN, M. 1993. Isolation by distance in equilibrium and non-equilibrium populations. Evolution 47:264-279.

SLATKIN, M. \& BARTON, N.H. 1989. A comparison of three indirect methods for estimating average levels of gene flow. Evolution 43:1349-1368.

SOKAL, R.R. 1979. Testing statistical significance of geographic variation patterns. Syst. Zool. 28:227-232.

SOKAL, R.R. \& ROHLF, F.J. 1995. Biometry. The principles and practice of statistics in biological research, 3rd ed. W.H. Freeman and Co., New York.

SOLTIS, D.E., HAUFLER, C.H., DARROW, D.C. \& GASTONY, G.J. Starch gel electrophoresis of ferns: a compilation of grinding buffers, gel and electrode buffers, and staining schedules. Am. Fern J. 73:9-27.

SOUSA, V.A. 2001. Population genetic studies in Araucaria angustifolia (Bert.) O. Ktze. Cuvillier Verlag, Göttingen.

STUBER, C.W., WENDEL, J.F., GOODMAN, M.M. \& SMITH, J.S.C. 1988. Techniques and scoring procedures for starch gel electrophoresis in enzymes from maize (Zea mays L.). Technical Bulletin 286, North Carolina State University, Raleigh.

VENCOVSKY, R. 1997. Biometrical approaches for molecular markers: estimation of effective population size. In International Workshop on Agricultural Biotechnology, 1997. Proceedings. ESALQ-USP, Piracicaba, Cook College - New Jersey Agricultural Experiment Station, The State University of New Jersey, Rutgers.

WAHLUND, S. 1928. Zusammensetzung von populationen und Korrelationserscheinungen vom Standpunkt der vererbungslehre aus betrachtet. Hereditas 11:65-106.

WALLACE, B. 1958. The comparison of observed and calculated zygotic distributions. Evolution 12:113-115.

WEIR, B.S. 1996. Genetic data analysis II: methods for discrete population genetic data. Sinauer Associates, Sunderland.

WORKMAN, P.L. 1969. The analysis of simple genetic polymorphisms. Human Biol. 41:97-114.

WRIGHT, S. 1969. Evolution and the genetics of populations. v.2. The theory of gene frequencies. The University of Chicago Press, Chicago.

WRIGHT, S. 1978. Evolution and the genetics of populations. v.4. Variability within and among populations. The University of Chicago Press, Chicago.
Título: Estrutura genética de populações naturais de Cryptocarya aschersoniana Mez (Lauraceae)através de marcadores isoenzimáticos

Autores: Pedro Luís Rodrigues de Moraes \& Maria Teresa Vitral de Carvalho Derbyshire

Biota Neotropica, Vol. 2 (número 2): 2003

http://www.biotaneotropica.org.br/v2n2/pt/ a b s tract ? a r tic 1 e + B N 02402022002

Recebido em 09/09/2002

Revisado em 30/10/2002

Publicado em 29/11/2002

ISSN 1676-0603

http://www.biotaneotropica.org.br 